\title{
Role of Electromagnetic Field Exposure in Childhood Acute Lymphoblastic Leukemia and No Impact of Urinary Alpha- Amylase - a Case Control Study in Tehran, Iran
}

\author{
Maral Mazloomi Tabrizi ${ }^{1 *}$, Seyed Ahmad Hosseini ${ }^{2}$
}

\begin{abstract}
Childhood acute lymphoblastic leukemia (ALL) is one of the most common hematologic malignancies which accounts for one fourth of all childhood cancer cases. Exposure to environmental factors around the time of conception or pregnancy can increase the risk of ALL in the offspring. This study aimed to evaluate the influence of prenatal and postnatal exposure to high voltage power lines on the incidence of childhood ALL. It also examines the role of various factors such as environmental factors and alpha-amylase as a marker in the development of leukemia.This cross-sectional case control study was carried out on 22 cases and 100 controls who born and lived in low socioeconomic families in Tehran and were hospitalized for therapeutic purposes in different hospitals ofrom 2013-2014. With regard to the underlying risk factors; familial history and parental factors were detected as risk factors of ALL but in this age, socioeonomic and zonal matched case control study, prenatal and childhood exposure to high voltage power lines was considered as the most important environmental risk factor $(\mathrm{p}=\mathbf{0 . 0 0 6}, \mathrm{OR}=3.651, \mathrm{CI} 95 \%$ 1.692-7.878). As the population study was from low socioeconomic state, use of mobiles, computers and microwaves was negligible. Moreover prenatal and postnatal exposure to all indoor electrically charged objects were not detected as significant environmental factors in the present study. This work defined the risk of environmental especially continuous pre and postnatal exposure to high voltage power lines and living in pollutant regions through the parents or children as well as the previously described risk factors of ALL for the first time in low socioeconomic status Iranian population.
\end{abstract}

Keywords: Leukemia - acute lymphoblastic leukemia (ALL) - childhood cancer - electromagnetic field

Asian Pac J Cancer Prev, 16 (17), 7613-7618

\section{Introduction}

Cancer has become as the second most common cause of death in developing countries (Roshandel et al., 2014) and childhood cancer is the second most common cause of death in children in developing countries (Lupo et al., 2014). Childhood cancer incidence has been increased by approximately $0.5 \%$ per year in united states (Hauri et al., 2013) and childhood acute lymphoblastic leukemia (ALL) has been considered as the most common hematologic and childhood malignancy which accounts for one fourth of all childhood cancer cases (Reisi et al., 2009).

Many epidemiologic studies have evaluated a wide range of maternal (Milne et al., 2015) and paternal nutritional factors as the major ethiologic factors of ALL (Bailey et al., 2014) but based on the largest number of childhood leukemia case study to date, risk of ALL could be reduced by maternal prenatal use of vitamins and folic acid. Moreover the association of ALL with parental education as a surrogate for lifestyle and sociodemographic characteristics has been recently suggested too (Metayer et al., 2014). Other than nutritional factors and the protective role of parental supplementation in risk reduction of ALL (Lupo et al., 2014), there are controversial evidences regarding the role of paternal residential and occupational exposures like paint (Bailey et al., 2014), PAHs (Deziel et al., 2014), pesticide exposures (Bailey et al., 2014), exposure to diagnostic radiological procedures (Bailey and Consortium, 2010) around the time of conception or pregnancy in increased risk of ALL in the offspring.

For many years, residential and occupational exposures to Electromagnetic fields (EMF) has been considered as possible human carcinogen , based on some epidemiological studies. These studies suggest the role of this exposure and increased risk of childhood leukemia, adult leukemia and adult brain tumors following chronic exposure to MF (D'Angelo et al., 2015). Because of limited evicdences on the ethiology of ALL in Iran ,we aimed in present study to analysis a wide range of utero exposure, maternal, paternal and childhood exposures,

${ }^{1}$ Department of Toxicology and Pharmacology, Faculty of Pharmacy, Pharmaceutical Sciences Branch, Islamic Azad University, ${ }^{2}$ Department of Occupational Hygiene, Faculty of Health Sciences, Shahid Beheshti University, Tehran, Iran *For correspondence: ma.mazlumi@gmail.com 
Identify biomarkers for early detection of cancer in people living in high-risk areas and provide practical solutions to avoid the disease, especially in children were the intended targets, in Tehran as one the most polluted cities of Iran in a case control setting.

\section{Materials and Methods}

\section{Population study}

A case-control cross sectional study was carried out among 22 newly diagnosed ALL and 100 normal children who were all $<12$ years, born and grown up in Tehran. Leukemia were identified from both self-reports registration and ALL was confirmed by evaluating their pathological reports. Urine samples were taken from both groups, and these samples for the measurement of alpha amylase in urine were determined by autoanalyzer. Exclusion criteria for cases and controls were lack of access to the parents, birth and living out of Tehran and having moderate and higher socioeconomic state. The control group was matched with cases for age \pm 5 years who born and lived in the same region.

\section{Electromagnetic fields (EMF)}

Living near high voltage power lines, using mobiles, computers, microwave and all indoor electrically charged objects were considered as the most important environmental factors Identification of environmental resources Exact living and working addresses of cases and controls were recorded and matched with the map of factories generating PAHs, dioxins, pesticides and other pollutants. A complete list of factories that release toxicants with hormone-like effects was provided before starting the study.

The families who lived within $4 \mathrm{~km}$ from the pollutant factories were considered as high risk family. Occupational exposures to chemicals, radiation, using plastic water and food containers through validated questionnaire.

\section{Identification of background variables}

Demographical variables were obtained from specific questionnaire items: A Delivery related factors including place of birth ,paternal and maternal ages at delivery ,BMI, education, job, socioeconomic states, physical activity, Personal history of any disorders , birth weight at delivery; familial history of Leukemia ,mother's irregular menstruation, marriage related factors including marital status of parents, age at marriage.

\section{Maternal related factors}

Information on hormone use was obtained from specific questionnaire items. They covered questions on ever and current use of oral contraceptive pills (OCPs), the brand names, age at start and total duration of the use. Other methods of contraception were recorded including use of intrauterine device, tubectomy and use of progestins. Pregnancy related factors including number of full-term pregnancies, age and maximum weight gain at each pregnancy, months of breast feeding at each delivery, history of abortion induction were recorded. History of infertility covered questions on years of infertility, i.e., more than 2 years without birth controlling methods, use of ovulation stimulating drugs, hormone therapy or history of in vitro fertilization. Patients were asked their gynecological disorders including ovarian cysts, uterine firoadenoma, irregular menstruation, hyrsutism and other disorders.

\section{Statistical Methods}

Values were expressed as percent per population or as the mean standard deviation. To assess associations between parametric variables student t-test and to evaluate nonparametric data, the chi square test was used. Relative risks and odds ratios were calculated by the Cochran-Mantel-Haenszel statistics using SPSS 16 and the odds ratios were reported for this case control retrospective study. When the odds ratio in cases was $>1$, if the probability values was $<0.05$ and when the $5 \%$ confidence interval of the true odds ratio was greater than 1 , then we interpreted it as significant risk factor. When the odds ratio in controls was $<1$, if the probability values was $<0.05$ and when the $5 \%$ confidence interval of the true odds ratio was less than 1 , then we interpreted it as protective factor.

\section{Results}

\section{Electromagnetic fields (EMF)}

In this age ,socioeonomic and zonal matched case control study prenatal and childhood exposure to high voltage power lines was considered as the most important environmental risk factors of ALL $(\mathrm{p}=0.006, \mathrm{OR}=3.651$, CI95\% 1.692-7.878). In fact $18.8 \%$ of ALL children had continuous exposure to high voltage power lines from prenatal time to 4 th age. As the population study was from low socioeconomic state, using mobiles , computers ,microwave was negligible. Moreover prenatal and postnatal exposure to all indoor electrically charged objects were not detected as significant environmental factors in present study.

\section{Identification of environmental resources}

Consumption of food and water from plastic containers in these children was considered as the second important risk factor $(\mathrm{p}<0.001, \mathrm{OR}=3.651$,CI $95 \%$ 1.689-7.631). Living near pollutant factories $(4<\mathrm{km})$ was considered as the next important risk factor of ALL $(p=0.006, O R=3.265$, CI95\%). The last factor out of 50 evaluated variables was sunlight exposure $(\mathrm{p}=0.029, \mathrm{OR}=1.048, \mathrm{CI} 95 \%=1.048-5.952)$ in this case control study (Table 1).

\section{Identification of familial background factors}

Out of 50 evaluated background factors, familial history of leukemia was considered as the the most imprtant risk factor of ALL in this young ( $<12$ years) population $(\mathrm{p}<0.001, \mathrm{OR}=8.143, \mathrm{CI} 95 \%$ 4.986-13.3). Parental history of occupational expoures was also considered as the second important risk factor of ALL $(\mathrm{P}<0.001, \mathrm{OR}=7.639$,CI 95\% 4.23-13.794). Other important background factors are ranked in Table 2. This study phase showed the role of parental X-ray exposure 
Table 1. Comparison of Prenatal and Childhood Environmental Exposures between ALL Cases and Controls

\begin{tabular}{|c|c|c|c|c|c|c|}
\hline \multirow[t]{2}{*}{ Characteristics } & \multirow[t]{2}{*}{ Case $(n=22)$} & \multirow[t]{2}{*}{ Control $(\mathrm{n}=100)$} & \multirow[t]{2}{*}{ P-Value } & \multirow[t]{2}{*}{ OR } & \multicolumn{2}{|c|}{ CI $95 \%$} \\
\hline & & & & & lower & Upper \\
\hline \multicolumn{7}{|c|}{ Prenatal Exposure to high voltage power lines } \\
\hline Yes & $4(18.18 \%)$ & $3(3 \%)$ & 0.006 & $3.651 *$ & 1.692 & 7.878 \\
\hline No & $18(81.81 \%)$ & $97(97 \%)$ & & & & \\
\hline \multicolumn{7}{|c|}{ Neonatal and childhood exposure to high voltage power lines ( $>4 \mathrm{yrs})$} \\
\hline Yes & $4(18.18 \%)$ & $3(3 \%)$ & 0.006 & $3.651^{*}$ & 1.692 & 7.878 \\
\hline No & $18(81.81 \%)$ & $97(97 \%)$ & & & & \\
\hline \multicolumn{7}{|c|}{ Keep food and water in plastic containers } \\
\hline Yes & $13(59.09 \%)$ & $22(22 \%)$ & $0.001>$ & $3.590 *$ & 1.689 & 7.631 \\
\hline No & $9(40.90 \%)$ & $78(78 \%)$ & & & & \\
\hline \multicolumn{7}{|c|}{ Living near pollutant factories $(4<\mathrm{km})$} \\
\hline Yes & $5(22.72 \%)$ & $5(5 \%)$ & 0.006 & $3.265^{*}$ & 1.529 & 6.971 \\
\hline No & $17(77.27 \%)$ & $95(95 \%)$ & & & & \\
\hline \multicolumn{7}{|c|}{ Sunlight exposure $(<2 \mathrm{hrs})$} \\
\hline Yes & $16(72.72 \%)$ & $47(47 \%)$ & 0.029 & $2.497 *$ & 1.048 & 5.952 \\
\hline No & $6(27.27 \%)$ & $53(53 \%)$ & & & & \\
\hline
\end{tabular}

Table 2. Comparison of Parental/Familial Risk Factors between ALL Cases and Controls

\begin{tabular}{|c|c|c|c|c|c|c|}
\hline \multirow[t]{2}{*}{ Characteristics } & \multirow[t]{2}{*}{ Case $(n=22)$} & \multirow[t]{2}{*}{ Control $(n=100)$} & \multirow[t]{2}{*}{ P-Value } & \multirow[t]{2}{*}{ OR } & \multicolumn{2}{|c|}{ CI $95 \%$} \\
\hline & & & & & Lower & Upper \\
\hline \multicolumn{7}{|c|}{ Familial history of leukemia } \\
\hline Yes & $8(36.36 \%)$ & $0(0 \%)$ & $0.001>$ & $8.143^{*}$ & 4.986 & 13.3 \\
\hline No & $14(63.63 \%)$ & $100(100 \%)$ & & & & \\
\hline \multicolumn{7}{|c|}{ Parental history of occupational exposures } \\
\hline Yes & $10(45.45 \%)$ & $2(2 \%)$ & $0.001>$ & $7.639 *$ & 4.23 & 13.794 \\
\hline No & $12(54.54 \%)$ & $99(99 \%)$ & & & & \\
\hline \multicolumn{7}{|c|}{ Exposure to X-rays around the time of conception or pregnancy } \\
\hline Yes & $3(13.63 \%)$ & $40(40 \%)$ & 0.019 & $4.222 *$ & 1.172 & 15.211 \\
\hline No & $19(86.36 \%)$ & $60(60 \%)$ & & & & \\
\hline \multicolumn{7}{|c|}{ Maternal severe stress around the time of conception or pregnancy } \\
\hline Yes & $6(27.27 \%)$ & $6(6 \%)$ & 0.002 & $3.438 *$ & 1.665 & 7.096 \\
\hline No & $16(72.72 \%)$ & $94(94 \%)$ & & & & \\
\hline \multicolumn{7}{|c|}{ Parental consanguinity } \\
\hline Yes & $8(36.3 \%)$ & $14(14 \%)$ & 0.014 & $2.597 *$ & 1.244 & 5.422 \\
\hline No & $14(63.63 \%)$ & $86(86 \%)$ & & & & \\
\hline \multicolumn{7}{|c|}{ Menstrual irregularities in Mothers before conception } \\
\hline Yes & $11(50 \%)$ & $26(26 \%)$ & 0.027 & $2.297 *$ & 1.095 & 4.821 \\
\hline No & $11(50 \%)$ & $74(74 \%)$ & & & & \\
\hline
\end{tabular}

before of at conception time, maternal severe stress in pregnancy ,parental consanguinity and menstrual irregularities in the mothers of ALL children when compared with normal children.

Alpha-amylase associated with underlying disease in children

This study shows a insignificant correlation with the underlying disease Alpha-amylase is measured in the urine. $(\mathrm{P}-$ Value $=0.286, \mathrm{OR}=3.651)$. The amount of children who have underlying disease $6.490+4.1810$ and $3.38484 .725+$ children who did not have this history was measured.

Alpha-amylase associated with underlying disease in the child's father

Having a history of underlying disease in the child's father was also a insignificant correlation between the amount of alpha amylase in the urine. (P-Value=0.985). The alpha-amylase derived from the urine of children with parents with a history of underlying disease in children $5.525+5.600$ and in the others 3.8752 .

Alpha-amylase associated with the mother's menstrual irregularities

Alpha amylase levels were measured in the urine of children with their mothers have menstrual irregularities $5.836+4.5564$ and 5.218+3.0106 in other children, this relationship is not significant $(\mathrm{P}-$ Value $=0.711)$.

Maternal exposure to X-rays

Alpha-amylase in the urine of children whose mothers were exposed to X-rays were determined 4.933+ 3.3561 and and in the other children 5.621+3.9200. this relationship is not significant $(\mathrm{P}-$ Value $=0.686)$

Alpha-amylase associated with Maternal exposure to electromagnetic fields during pregnancy

Mothers exposed to electromagnetic fields during pregnancy, with no significant relationship between 
Table 3. Alpha-amylase in Urine Associated with Different Risk Factors

\begin{tabular}{|c|c|c|}
\hline Total population & Alpha Amylase (mean+ SD) & p-value \\
\hline Background history of disease (+) & $6.490+4.1810$ & \multirow{2}{*}{0.286} \\
\hline Background history of disease (-) & $4.725+3.3848$ & \\
\hline Background history of disease in father $(+)$ & 5.600 & \multirow{2}{*}{0.985} \\
\hline Background history of disease in father (-) & $5.525+3.8752$ & \\
\hline Menstrual irregularities in Mother $(+)$ & $5.836+4.5564$ & \multirow{2}{*}{0.711} \\
\hline Menstrual irregularities in Mother (-) & $5.218+3.0106$ & \\
\hline Exposure to X-rays (+) & $4.933+3.3561$ & \multirow{2}{*}{0.778} \\
\hline Exposure to X-rays (-) & $5.621+3.9200$ & \\
\hline Parental consanguinity $(+)$ & $5.163+3.8116$ & \multirow{2}{*}{0.741} \\
\hline Parental consanguinity (-) & $5.736+3.8925$ & \\
\hline Keep food and water in plastic containers(+) & $5.477+2.9161$ & \multirow{2}{*}{0.942} \\
\hline Keep food and water in plastic containers(-) & $5.600+4.9777$ & \\
\hline Placing the child in the sun(+) & $5.181+3.4049$ & \multirow{2}{*}{0.497} \\
\hline Placing the child in the sun(-) & $6.450+4.8870$ & \\
\hline The mother of computer use in pregnancy $(+)$ & $5.233+3.3650$ & \multirow{2}{*}{0.889} \\
\hline The mother of computer use in pregnancy (-) & $5.574+3.925$ & \\
\hline The mother of computer use in breastfeeding $(+)$ & $5.233+3.3650$ & \multirow{2}{*}{0.889} \\
\hline The mother of computer use in breastfeeding (-) & $5.574+3.9257$ & \\
\hline Maternal exposure during pregnancy to high voltage power lines(+) & $7.575+5.8517$ & \multirow{2}{*}{0.24} \\
\hline Maternal exposure during pregnancy to high voltage power lines(-) & $5.072+3.2278$ & \\
\hline Mother during breastfeeding exposure to high voltage power lines $(+)$ & $7.575+5.8517$ & \multirow{2}{*}{0.24} \\
\hline Mother during breastfeeding exposure to high voltage power lines(-) & $5.072+3.2278$ & \\
\hline Children exposed to high voltage power lines $(+)$ & $7.575+5.8517$ & \multirow{2}{*}{0.24} \\
\hline Children exposed to high voltage power lines(-) & $5.072+3.2278$ & \\
\hline
\end{tabular}

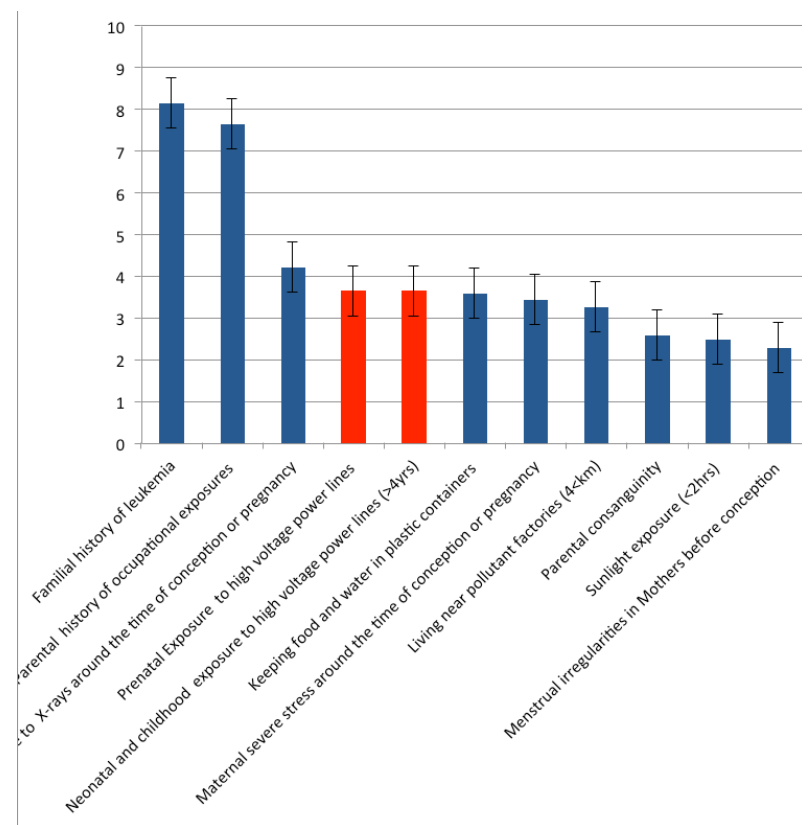

Figure 1. Ranking of ALL Risk Factors According to the Odds Ratios

the amount of alpha amylase in urine) P- Value $=0.240($ And for mothers during pregnancy were exposed to electromagnetic fields $7.575+5.8517$. also for mothers during pregnancy were not exposed to electromagnetic fields $5.072+3.2278$. Similarly, during lactation, and after birth.

Alpha-amylase relationship with the baby in the sun

In this study, children exposed to sunlight, with no significant association between alpha amylase in urine is measured. $(\mathrm{P}-$ Value $=0.497)$. Alpha-amylase levels in the urine tests that children who are exposed to sunlight $(<2$ houes per day) $5.181+3.4049$ And in children with no exposure ( $>2$ houes per day) $6.450+4.8870$.

Alpha-amylase relationship with Maternal use of computers during pregnancy

Maternal use of computers during pregnancy does not show a significant correlation with the amount of alpha amylase in urine children. (P-Value=0.157). In children whose mothers using the computer during pregnancy $5.233+3.3650$. And $5.574+3.9257$ in the other children.

Alpha-amylase relationship with Maternal use of computers during Breast-feeding

Maternal use of computers during Breast-feeding also showed insignificant relationship with the amount of alpha-amylase in urine in the children. (P-Value $=0.889)$. $5.233+3.3650$ in children whose mothers using the computer during Breast-feeding and 5.072+3.2278 were determined in the other children. 


\section{Discussion}

Recent evidences according to epidemiological studies, support a clear association between socioeconomic status and increased risk of childhood cancers (Hashemizadeh et al., 2013), (Njoku et al., 2013) especially in ALL (Metayer $\mathrm{C}$ et al., 2014). This study tried to find the possible risk factors of ALL in low socioeconomic population in industrial regions of Tehran by focusing on the role of electromagnetic fields for the first time in this group of patients in Iran.

Several local epidemiological studies have been conducted in different provinces of Iran including Mazandaran (Tahmasby et al., 2013), Golestan (Rajabli et al., 2013) and Khorasan Razavi (Hashemizadeh et al., 2013)on the prevalence of Leukemia and its possible risk factors. Although the obtained findings in the last study showed clear differences in the incidence rates of Leukemia based on age, gender, residence, and type of malignancy, ALL was considered as the most prevalent type of leukemia. For this reasons we focused on the paternal, maternal background factors, prenatal and postnatal environmental exposures and Alpha-amylase relationship with that factors in Tehran as a city with higher levels of air pollution (Rashidi et al., 2013) (Janghorbani et al., 2013) and soil pollution (Mohajer et al., 2013). We considered here 11 most significant causes and considered the specific role of prenatal and postnatal (>4yrs) exposure to high voltage power lines as the most important environmental risk factors of ALL ( $\mathrm{p}=0.006$,OR $=3.651, \mathrm{CI} 95 \% 1.692-7.878)$. For some childhood cancers , such as acute lymphoblastic leukemia (ALL), there is evidence of an embryonic cell of origin (Marshall GM et al., 2014) therefore we assessed the prenatal factors in this study at the first part of assessments and found the dramatic carcinogenic effects of living near high voltage power lines in prenatal and postnatal periods.

We observed in present setting that the incidence of leukemia in first degree family of patients may increase the ALL risk more than 8 times $(\mathrm{p}<0.001, \mathrm{OR}=8.143, \mathrm{CI}$ 95\% 4.986-13.3) and considered the other factors (Figure 1). This results confirm the role of family cancer history which was previously considered in a population-based case-control study in chronic lymphocytic leukemia cases. This study in Baltimore suggested a genetic component for leukemia occurrence in several case families, although the majority of cases of leukemia appeared to be sporadic (Zierhut et al., 2012).

In present work we considered the etiology of ALL for the first time in Iranian population but despite the significant role of family history, the rest of children 14 $(63.63 \%)$ didn't have any history of malignancy in their first degrees and urge the scientists to evaluate the role of environmental factors.

The second ranked important background factor was parental occupational exposures. Out of 22 patients, 10 children $(45.45 \%$ vs. $2 \%)$ showed paternal exposure to chemicals (diesel oil, gasoline, paints, insecticides, pesticides, herbicides, and chemical fertilizers) before and at the conception time or paternal working experiences in agriculture and forestry before pregnancy, leather processing, decoration, and vehicle repair $(\mathrm{P}<0.001$, $\mathrm{OR}=7.639$, CI 95\% 4.23-13.794) which was in accordance with results of a parallel work in one recent study in China (Shi et al., 2013).

Identify biomarkers for early detection of cancer in people living in high-risk areas And provide practical solutions to avoid the disease, especially in children was intended purpose.

According to studies of valuable papers and the results of tests, Alpha-amylase as a marker can not be considered specific for leukemia.

This work has defined the forces of environmental exposures especially continuous pre and post natal exposure to high voltage power lines and living in pollutant regions through the parents or children as well as the role of previously described risk factors of ALL for the first time in low socioeconomic Iranian population. We confirmed here a new risk factor for ALL and suggest the hypothesis on embryonic origin of many other cancers which should be assessed in next studies in larger case control studies.

According to studies of valuable papers and according to the results of the tests, Alpha-amylase can not be considered as a biomarker specific for leukemia.

\section{References}

Bailey HD, Armstrong BK, de Klerk NH et al (2010). Exposure to diagnostic radiological procedures and the risk of childhood acute lymphoblastic leukemia. Cancer Epidemiol Biomarkers Prev, 19, 2897-909.

Bailey HD, Fritschi L, Metayer C et al (2014). Parental occupational paint exposure and risk of childhood leukemia in the offspring: findings from the childhood leukemia international consortium. Cancer Causes Control, 25, 1351-67.

Bailey HD, Fritschi L, Infante-Rivard C et al (2014). Parental occupational pesticide exposure and the risk of childhood leukemia in the offspring: findings from the childhood leukemia international consortium. Int J Cancer, 135, 2157-72.

Bailey HD, Miller M, Greenop KR et al (2014). Paternal intake of folate and vitamins B6 and B12 before conception and risk of childhood acute lymphoblastic leukemia. Cancer Causes Control, 25, 1615-25.

D'Angelo C, Costantini E, Kamal MA et al (2015). Experimental model for ELF-EMF exposure: Concern for human health. Saudi J Biol Sci, 22, 75-84.

Deziel NC, Rull RP, Colt JS et al (2014). Polycyclic aromatic hydrocarbons in residential dust and risk of childhood acute lymphoblastic leukemia. Environ Res, 133, 388-95.

Hashemizadeh H, Boroumand H, Noori R et al (2013). Socioeconomic status and other characteristics in childhood leukemia. Iran J Ped Hematol Oncol, 3, 182-6.

Hauri D, Spycher B, Huss A et al (2013). Domestic radon exposure and risk of childhood cancer: a prospective censusbased cohort study. Environ Health Perspect, 12, 1239-44.

Janghorbani M, Piraei E (2013). Association between air pollution and preterm birth among neonates born in Isfahan, Iran. J Res Med Sci, 18, 875-81.

Lupo PJ, Dietz DJ, Kamdar KY et al (2014). Gene-environment interactions and the risk of childhood acute lymphoblastic leukemia: exploring the role of maternal folate genes and folic Acid fortification. Pediatr Hematol Oncol, 31, 160-8. 
Maral Mazloomi Tabrizi and Seyed Ahmad Hosseini

Marshall GM, Carter DR, Cheung BB et al (2014). The prenatal origins of cancer. Nat Rev Cancer, 14, 277-89.

Metayer C, Milne E, Dockerty JD, (2014). Maternal supplementation with folic acid and other vitamins and risk of leukemia in offspring: a childhood leukemia international consortium study. Epidemiol, 25, 811-22.

Milne E, Greenop KR, Scott RJ et al (2015). Folate pathway gene polymorphisms, maternal folic Acid use, and risk of childhood acute lymphoblastic leukemia. Cancer Epidemiol Biomarkers Prev, 24, 48-56.

Mohajer R, Salehi MH, Mohammadi J et al (2013). The status of lead and cadmium in soils of high prevalenct gastrointestinal cancer region of Isfahan. J Res Med Sci, 18, 210-4.

Njoku K, Basta N, Mann KD et al (2013). Socioeconomic variation in survival from childhood leukaemia in northern England, 1968-2010. Br J Cancer, 108, 2239-45.

Rajabli N, Naeimi-Tabeie M, Jahangirrad A et al.(2013). Epidemiology of leukemia and multiple myeloma in Golestan, Iran. Asian Pac J Cancer Prev, 14, 2233-6.

Rashidi M, Ramesht MH, Zohary M et al (2013). Relation of air pollution with epidemiology of respiratory diseases in isfahan, Iran from 2005 to 2009. J Res Med Sci, 18, 1074-9.

Reisi N1, Azhir A, Hashemipour M et al (2009). The metabolic syndrome in survivors of childhood acute lymphoblastic leukemia in Isfahan, Iran. J Res Med Sci, 14, 111-6.

Reisi N, Azhir A, Hashemipour M et al (2014). A diversity of cancer incidence and mortality in west Asian populations. Ann Glob Health, 80, 346-357.

Shi R, Gao Y, Zhang Y et al (2013). Relationship between parental exposure to chemicals and risk of childhood acute leukemia. Zhonghua Lao Dong Wei Sheng Zhi Ye Bing Za Zhi, 31, 413-7.

Tahmasby B, Marnani AB, Maleki M et al (2013). Blood malignancies in mazandaran province of Iran. Asian Pac J Cancer Prev, 14, 1053-6.

Zierhut H, Linet MS, Robison LL et al (2012). Family history of cancer and non-malignant diseases and risk of childhood acute lymphoblastic leukemia: a Children's Oncology Group Study. Cancer Epidemiol, 36, 45-51. 